\title{
The calculation of phenotypic and genetic parameters for milk urea concentration in Holstein breeds
}

\author{
Draženko Budimir ${ }^{1, *}$, Pero Mijić ${ }^{2}$, and Vesna Gantner $^{2}$ \\ ${ }^{1}$ Agricultural Cooperative „Livač“, Aleksandrovac bb, 78250 Laktaši, Bosnia and Herzegovina \\ ${ }^{2}$ Faculty of Agrobiotechnical Sciences Osijek, Vladimira Preloga, 1, Osijek, Croatia
}

\begin{abstract}
Heritability (0.08) was evaluated in a model whereas the comparable group was used the interaction between the herd and the control day. The influence of the herd was used as a comparable group and heritability $(0.03)$. The interaction between herds and years of testing was used as a comparable group (0.04 and 0.05). Heritability (0.08) was evaluated in a model a comparable group was used the interaction between the herd and the control day. Phenotypic correlations between milk urea concentration and milking traits: daily quantity of milk, and the content of fat and proteins $(\mathrm{P}<0.0001)$. Positive and low phenotypic correlation $(0.15)$ was found between the milk urea concentration and daily milk yield, between the urea concentration and the daily amount of fat $(0.10)$. Between the urea concentration and milk fat content coefficient was $(-0.05)$, between urea concentration and protein content $(0.03)$.
\end{abstract}

\section{Introduction}

Genetic improvement of the population is achieved by selecting superior animals for the parents of the next generations of offspring. From the standpoint of quantitative genetics, each individual passes on 'half' of its genes to offspring.

The genotypic value of an individual is equal to the sum of the gene effects and the interaction between the genes. Only genes are passed from parent to offspring, which represents the additive genetic value of the animal. The remainder of the genotypic value is non-additive and represents genetic interactions (dominance and epistasis) that cannot be passed from parent to offspring. The additive genetic value is also called the breeding value.

Assessment of breeding value requires, in addition to production data and origin, assessed genetic parameters (heritability and genetic correlations). Positive genetic correlations between production traits allow for the simultaneous improvement of multiple traits, while negative ones cause the improvement of one and the erosion of another trait.

\footnotetext{
${ }^{*}$ Corresponding author: drazenkobudimir@hotmail.com
} 
Phenotypic correlations of urea with respect to production traits, such as milk fat content and milk quantity $[9,10,5]$ are low. State that the correlation between urea content and somatic cell count was very high (0.89) [8].

Assessment of heritability is required to assess breeding values. Generally speaking, heritability represents the share of genetic in total phenotypic variance.

The estimation of heritability for the property of urea content in milk is between $6 \%$ and $44 \%$. Calculated the heritability value for urea content in milk in the range of 0.13 to 0.22 [5].

In their paper, [8] determined the heritability value for urea content of 0.14 . Research done in Sweden calculated heritability in the interval of 0.16-0.18 in Holstein cows [6].

Values in the estimate differ between populations due to data structure, calculation methods, and effects used in the model. The effect affects the assessment of heritability only when included in a random part of the model.

The assessed heritability is specific not only for a given population, but is also conditioned by the environment. If the environmental conditions are constant then the higher the value of the estimated heritability.

\section{Material and methods}

The subject research included records of urea content obtained during the milk control of Holstein cows. Determinations of milk yield in the analyzed heads were performed by regular monthly controls, AT4 or BT4 method [3]. Each record of the animal on the control day included individual data on the animal, ie its life number, date of birth and date of last calving, as well as information on the ordinal number and stage of lactation, age at calving, calving season. Records of the first to tenth lactations of cows were used in the analysis. Due to the small number of records of daily lactation controls, data from the eighth to the tenth lactation were associated with data from the seventh to one common class $(7+)$. The lactation stage was determined by the number of days between the date of the last calving of the cow and each control day during lactation. The duration of lactation was limited to 400 days. The first heifers calved at the age of 20 to 40 months, while the age of the cows in the second calving ranged from 32 to 56 months. During data processing, data that lacked or were illogical data on date of birth, date of last calving or date of control, and region were excluded from the analysis. Daily controls that came from an unknown herd and if the herd has less than three controlled cows within the same year were also deleted. Logical eligibility limits have also been set in accordance with ICAR rules, standards and guidelines within which the values for the observed property in the analysis are located. The interval of urea concentration in milk ranging between 1 and $70 \mathrm{mg} / 100 \mathrm{ml}$ was observed. Records where urea content is outside the specified range are not included in the analysis. After the preparation of data for further analysis, 2,109,598 records of the daily milk yield of 114,768 cows that calved in the period from January 2003 to December 2012 were used. Production data, as well as origin data, were coded in the SAS software package [7] before evaluating the components of variance.

Data on origin (so-called "pedigree file") include family ties between animals. This file includes all cows with production data (daily controls) and their ancestors i.e. kinship spanning five generations (Table 1). 
Table 1. Number of animals by generation and sex

\begin{tabular}{|c|c|c|c|c|c|c|c|c|c|c|c|c|c|c|}
\hline \multirow{3}{*}{ Sex } & \multicolumn{12}{|c|}{ Number of generations in origin } & \multirow{2}{*}{\multicolumn{2}{|c|}{ Total }} \\
\hline & \multicolumn{2}{|c|}{0} & \multicolumn{2}{|c|}{1} & \multicolumn{2}{|c|}{2} & \multicolumn{2}{|c|}{3} & \multicolumn{2}{|c|}{4} & \multicolumn{2}{|c|}{5} & & \\
\hline & $\mathrm{n}$ & $\%$ & $\mathrm{n}$ & $\%$ & $\mathrm{n}$ & $\%$ & $\mathrm{n}$ & $\%$ & $\mathrm{n}$ & $\%$ & $\mathrm{n}$ & $\%$ & $\mathrm{n}$ & $\%$ \\
\hline M & & & 6,519 & 3.9 & 1,052 & 0.6 & 552 & 0.3 & 289 & 0.2 & 41 & 0.0 & 8,453 & 5.1 \\
\hline $\mathrm{F}$ & 124,854 & 74.9 & 18,969 & 11.4 & 7,986 & 4.8 & 4,144 & 2.5 & 2,184 & 1.3 & 57 & 0.0 & 158,194 & 94.9 \\
\hline Total & 124,854 & 74.9 & 25,488 & 15.3 & 9,038 & 5.4 & 4,696 & 2.8 & 2,473 & 1.5 & 98 & 0.1 & 166,647 & 100.0 \\
\hline
\end{tabular}

The pedigree file contains a total of 166,647 animals. With zero generation were marked cows that had production data and they represented about $75 \%$ of the total number of animals in origin. The fathers and mothers of these cows represent the first generation of animals and together make up $15.3 \%$ of the total number of animals. The cows were descendants of 6,519 bulls, or 18,969 cows. As expected, the proportion of animals decreases with generation of origin.

\section{Result and discussion}

Model selection. The selection of the model used to calculate the components of variance and the assessment of breeding values includes influences in the fixed and in the random part of the model, which significantly affected the variability of urea content. The selection of influences was carried out on the basis of a model using milk yield data on the control day, in which lactation was defined as a repeatable measurement, while the lactation stage was described in the fixed part of the model. The development of the fixed part of the model and the definition of the impact is based on the coefficient of determination (R2), the degree of freedom (df) and the share of variability explained by the individual impact.

The selected model includes the following fixed influences with classes: ordinal number of lactation, county and calving season defined as the interaction between the year and three consecutive months of calving. The influence of age at first calving was described by quadratic regression, and the lactation stage was modeled by an Ali-Schaeffer lactation curve nested within the ordinal number of lactation. Mean values were assessed for fixed impacts. The model used explained $6.8 \%$ of the variability for the urea content property. In the random part of the model, in addition to the additive genetic influence, the random influence of the interaction of the herd and the day of control was also included.

Phenotypic correlations as a measure of the relationship between traits allow the values of one trait to be predicted with a certain probability based on knowledge of the value of another. In the present study, phenotypic correlations between urea content and observed milk traits were calculated, the values of which are collected during regular milk control and are found in the analyzed data set: daily milk quantity, daily quantity and fat and protein content.

As can be seen from Table 2, the obtained values of phenotypic correlations were statistically significant $(\mathrm{P}<0.0001)$. The calculated phenotypic correlations between the observed traits are low, which indicates the fact that with little probability we can predict how the value of the observed traits correlated with the urea content will change. 
Table 2. Phenotypic correlations between urea content and milk yield traits

\begin{tabular}{|c|c|c|c|c|c|}
\hline Attribute & Milk, $\mathrm{kg}$ & Fat, \% & Fat, $\mathrm{kg}$ & Proteins, \% & Proteins, $\mathrm{kg}$ \\
\hline $\begin{array}{c}\text { Urea } \\
\text { content }\end{array}$ & 0,15 & $-0,05$ & 0,10 & 0,03 & 0,16 \\
\hline
\end{tabular}

Positive and low phenotypic correlation $(0.15)$ was found between urea content and daily milk yield. Positive values of the correlation coefficient were also found between the urea content and the daily amount of fat $(0.10)$ and between the urea content and the amount of protein $(0.16)$.

The correlation coefficient between urea content and milk fat content was low and negative $(-0.05)$, while between urea content and protein content it was low and positive ($0.03)$.

Components of variance for urea content were estimated in the VCE-6 software package [4], using the REML method. Based on the literature citations, the following influences were tested in the randomized part of the fixed regression model: additive genetic influence, comparable group (herd, herd interaction and year of testing, herd interaction and control day) and permanent environmental influence.

As can be seen from Table 3, the tested models differed in the definition of the comparable group. The lowest value of heritability (0.03) was assessed by a model where the influence of herd was used as a comparable group.

In the second and third models, where the interaction of herd and year of testing was used as a comparable group, higher values of heritability (0.04 and 0.05$)$ were evaluated compared to the previous model. The third model differed from the second in that it did not involve the permanent impact of the environment.

In the fourth model, which includes both the influence of the herd and the interaction of the herd and the control day as a comparable group, the estimated value of heritability was 0.06 . The highest value of heritability $(0.08)$ was evaluated in the fifth model, where the interaction between the herd and the control day was used as a comparable group.

Table 3. Estimation of variance components for urea content property using different models

\begin{tabular}{|c|c|c|c|c|c|c|c|}
\hline Model & Impacts & $h^{2}$ & $p^{2}$ & $c_{h}{ }^{2}$ & $c_{h y}{ }^{2}$ & $c_{h t d d^{2}}$ & $e^{2}$ \\
\hline 1 & $\begin{array}{l}\mathrm{a}+c_{h}+\mathrm{p} \\
+\mathrm{e}\end{array}$ & $\begin{array}{c}0,03 \pm \\
0,001\end{array}$ & $\begin{array}{c}0,09 \pm \\
0,001\end{array}$ & $\begin{array}{c}0,25 \\
\pm 0,004\end{array}$ & / & I & $\begin{array}{c}0,63 \pm \\
0,003\end{array}$ \\
\hline 2 & $\begin{array}{l}\mathrm{a}+c_{h y}+\mathrm{p} \\
+\mathrm{e}\end{array}$ & $\begin{array}{c}0,04 \pm \\
0,001\end{array}$ & $\begin{array}{c}0,01 \pm \\
0,002\end{array}$ & 1 & $\begin{array}{c}0,34 \pm \\
0,001\end{array}$ & / & $\begin{array}{c}0,61 \pm \\
0,002\end{array}$ \\
\hline 3 & $\mathrm{a}+c h y+\mathrm{e}$ & $\begin{array}{c}0,05 \pm \\
0,002\end{array}$ & & & $\begin{array}{c}0,33 \pm \\
0,002\end{array}$ & I & $\begin{array}{c}0,62 \pm \\
0,001\end{array}$ \\
\hline 4 & $\begin{array}{l}\mathrm{a}+c_{h}+ \\
c_{h t d}+\mathrm{e}\end{array}$ & $\begin{array}{c}0,06 \pm \\
0,001\end{array}$ & & $\begin{array}{c}0,19 \\
\pm 0,003\end{array}$ & & $\begin{array}{c}0,53 \\
\pm 0,003\end{array}$ & $\begin{array}{c}0,22 \pm \\
0,001\end{array}$ \\
\hline 5 & $\mathrm{a}+c_{h t d}+\mathrm{e}$ & $\begin{array}{c}0,08 \pm \\
0,001\end{array}$ & I & I & I & $\begin{array}{c}0,67 \\
\pm 0,001\end{array}$ & $\begin{array}{c}0,25 \pm \\
0,001\end{array}$ \\
\hline
\end{tabular}

Where: h2 - heritability, p2 - share of permanent environment, ch2 - share for herd, chy2 - share for herd-years of testing, chtd2 - share for herd-control day, e2 - rest (unexplained part)

The permanent environmental impact included in the first and second models explained the small share of variability $(1 \%$ and $9 \%)$. For this reason, it was not included in other models. The herd as a comparable group explained the smallest share of variability $(25 \%$ 
and 19\%) compared to the herd-year interaction year $(33 \%$ and $34 \%)$ and the impact defined as herd interaction and control day (53\% and 67\%).

The unexplained portion of variability was greatest in models where the herd was used as a comparable group (63\% and 61\%, respectively). In the models where the herd-control interaction was used, this proportion was the lowest (22\% and $25 \%$, respectively).

A fifth model was used to calculate breeding values. This model evaluated the highest value of heritability with a low proportion of unexplained variability. Estimated culture values ranged from $-6.42 \mathrm{mg} / 100 \mathrm{ml}$ to $13.31 \mathrm{mg} / 100 \mathrm{ml}$ (Table 4). This range was narrower for bulls than for cows since bulls get results based on a larger number of offspring, compared to cows.

Table 4. Descriptive statistics of absolute and standardized breeding values and accuracy of assessment for the property urea content

\begin{tabular}{|l|l|c|c|c|}
\hline \multicolumn{2}{|l|}{ Descriptive statistics - official ratings } & M & F & Sum \\
\hline \multirow{4}{*}{ Breeding value } & Number (N) & 1.146 & 108.726 & 109.872 \\
\cline { 2 - 5 } & Average & 0,34 & 0,13 & 0,13 \\
\cline { 2 - 5 } & Std & 1,35 & 1,31 & 1,31 \\
\cline { 2 - 5 } & Min & $-4,98$ & $-6,42$ & $-6,42$ \\
\cline { 2 - 5 } & Max & 5,76 & 13,31 & 13,31 \\
\hline \multirow{4}{*}{$\begin{array}{l}\text { Standardized } \\
\text { value }\end{array}$} & breeding & 1.146 & 108.726 & 109.872 \\
\cline { 2 - 5 } & Average & 100,03 & 99,86 & 99,88 \\
\cline { 2 - 5 } & Std & 12,01 & 12,10 & 12,11 \\
\cline { 2 - 5 } & Min & 64,19 & 64,05 & 64,05 \\
\cline { 2 - 5 } & Max & 147,90 & 147,99 & 147,99 \\
\hline \multirow{5}{*}{ Accuracy } & Number (N) & 1.146 & 108.726 & 109.872 \\
\cline { 2 - 5 } & Average & 0,71 & 0,55 & 0,55 \\
\cline { 2 - 5 } & Std & 0,15 & 0,11 & 0,11 \\
\cline { 2 - 5 } & Min & 0,50 & 0,35 & 0,35 \\
\cline { 2 - 5 } & Max & 1,00 & 0,84 & 1,00 \\
\hline
\end{tabular}

Standardization of breeding values is a procedure by which breeding values are standardized to a certain average and standard deviation for easier understanding and interpretation for publication.

In Central Europe, breeding values are standardized to a mean value of 100, while the deviation for one standard deviation is $+/ 12$ points.

The largest share of breeding values of bulls is around the average due to the fact that a large share of bulls has a small number of offspring or daughters. Given that cows in each population make up the majority ( $98 \%$ in the study in question, Fig. 1$)$, the distribution is without major deviations from the normal curve. Only official breeding values are shown in Table 1 . The reliability criterion is the reliability of the estimated breeding value of $50 \%$. 


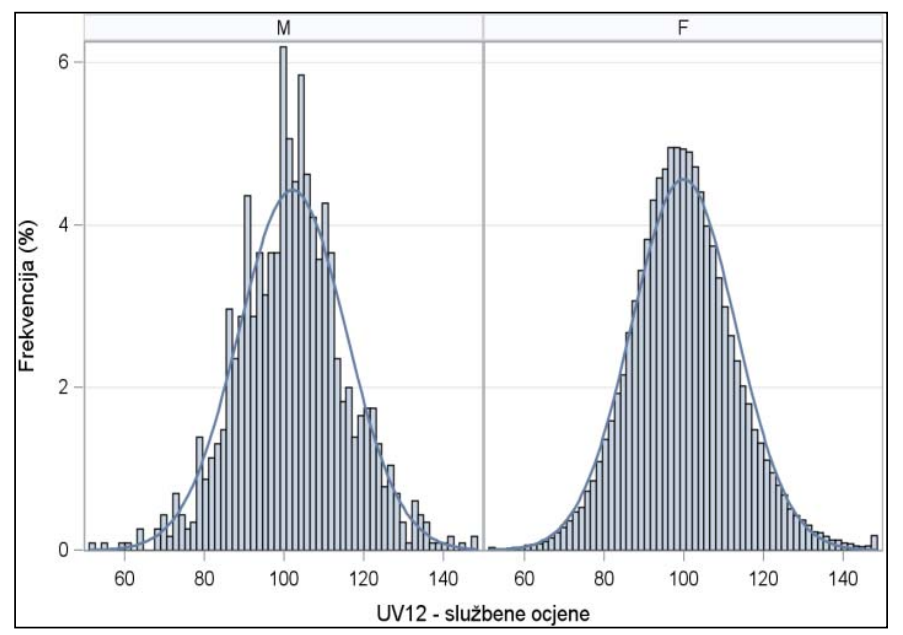

Fig. 1. Distribution of standardized breeding values for the property urea content by sex

The genetic trend (Fig. 2) for the property of urea content was calculated as a linear regression of breeding values of animals by year of birth. A positive genetic trend was observed in the period from 2000 to 2007. In the last two years of the observed period, there was a decrease in average breeding values.

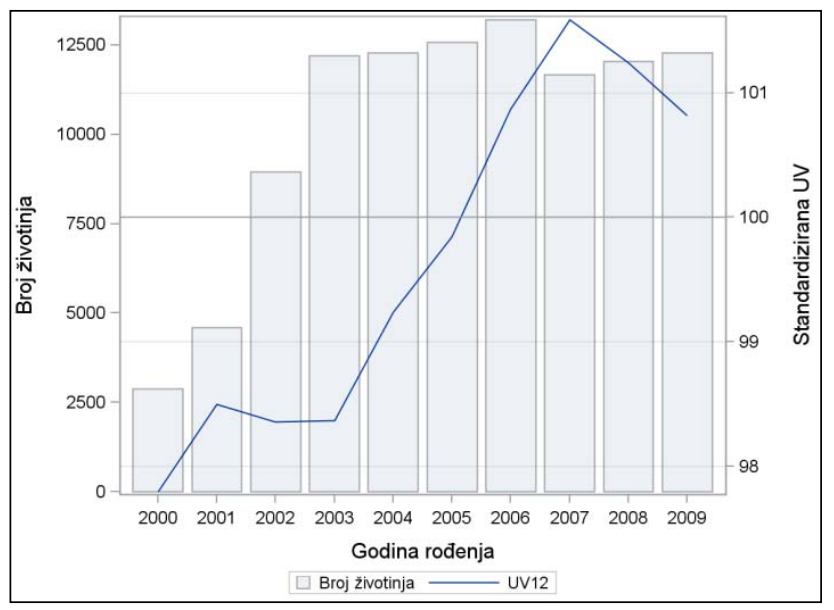

Fig. 2. Genetic trend for urea content property

The assessment of the components of variance precedes the assessment of breeding values. Five test-day models with daily records were tested in order to obtain optimal values of heritability with the smallest possible share of unexplained variability. The models differed from each other in the definition of a comparable group. The lowest value of heritability (0.03) was assessed by a model where the influence of herd was used as a comparable group. In models where the interaction between herd and year of testing was used as a comparable group, higher heritability values $(0.04$ and 0.05$)$ were evaluated compared to the previous model. The third model differed from the second in that it did not involve the permanent impact of the environment.

The highest value of heritability $(0.08)$ was evaluated by a model where the interaction between the herd and the control day was used as a comparable group. It is known from the literature that heritability for the property of urea content in milk is between $6 \%$ and $44 \%$ 
$[1,10,2,8]$. These estimated values differ between populations due to the data structure, calculation methods, and effects used in the model. In their paper, [8] determined the heritability value for urea content of 0.14 . In the present study, the share of variability explained by the herd-day control interaction was $67 \%$, while $25 \%$ of the variability of urea content remained unexplained.

In the present study, the calculated phenotypic correlations between urea content and milk yield characteristics: daily milk quantity, daily quantity and fat and protein content were statistically significant $(\mathrm{P}<0.0001)$. A positive and low phenotypic correlation $(0.15)$ was found between the urea content and the daily amount of milk, between the urea content and the daily amount of fat $(0.10)$, and between the urea content and the amount of protein (0.16). The correlation coefficient between urea content and milk fat content was low and negative (-0.05), while between urea content and protein content it was low and positive (0.03). The calculated phenotypic correlations between the observed traits are low, which indicates the fact that we can with little probability predict how the value of the observed traits that correlate with the urea content will change. Researche found negative phenotypic correlations between urea content in milk and milk quantity and percentage of milk fat [1]. In a study by [2] also found a negative correlation (-0.05) between urea content in milk and milk production, but also a correlation close to zero $(0.0001)$ for milk fat content. The amount and protein content were positively correlated $(0.03$ and 0.16$)$ with the urea content. Low phenotypic correlations between urea content and milk fat content and between urea content and milk content were found in Holstein cows [9, 10,5].

One of the future activities is the calculation of genetic correlations between urea content and milk yield traits to determine whether selection on urea content simultaneously leads to improvement or erosion of other milk yield traits.

\section{Conclusion}

The random part of the model contains direct additive genetic influence and herd-day control interaction.

The estimated heritability for urea content was 0.08 . The proportion of variance assessed by the effect of herd-day control interaction was $0.67 .25 \%$ of the total variability of urea content remained unexplained.

Statistically significant correlation coefficients $(\mathrm{P}<0.0001)$ were found between urea content and milk yield properties. Positive and low phenotypic correlation $(0.15)$ was found between urea content and daily milk yield. Positive values of the correlation coefficient were also found between the urea content and the daily amount of fat $(0.10)$, and the urea content and the amount of protein (0.16). The correlation coefficient between urea content and milk fat content was low and negative $(-0.05)$, while between urea content and protein content it was low and positive (-0.03).

The results presented in the present study indicate that the model with daily records and fixed regression can be used for genetic evaluation of the urea content of Holstein cattle breed in Croatia

Further research should include the development of a model that would include other milk traits to determine genetic correlations between traits and allow for the simultaneous genetic progression of multiple traits.

\section{References}

1. G.A. Broderick, M.K. Clayton, Journal of Dairy Science, 80, 2964 (1997) 
2. S.M. Godden, K.D. Lissemore, D.F. Kelton, K.E. Leslie, J.S. Walton, J.H. Lumsden, Journal of Dairy Science, 84, 107 (2001)

3. ICAR - International Committee for Animal Recording, Guidelines approved by the General Assembly held in Cork, Ireland, June (2012)

4. M. Kovač, E. Groeneveld, L.A. Garcia Cortes, VCE-5 User's a package forestimation of dispersion parameters. 7th WCGALP, Montpellier, France, 19-23 Aug. (2002)

5. R.G. Mitchell, G.W. Rogers, C.D. Dechow, J.E. Vallimont, J.B. Cooper, U. SanderNielsen, J.S. Clay, Journal of Dairy Science, 88, 4434 (2005)

6. S. Mucha, E. Strandberg, Journal of Dairy Science, 94, 5665 (2011)

7. SAS, Inst. Inc 2001. Version 8.2. Cary,NC, SAS Institute Inc.

8. W.M. Stoop, H. Bovenhuis, J.A.M. van Arendonk, Journal of Dairy Science, 90, 1981 (2007)

9. A.Wenninger, O. Distl, Dtsch Tierartzl Wochenschr, 100, 405 (1993)

10. G.M. Wood, P.J. Boettcher, J. Jambrozik, G.B. Jansen, D.F. Kelton, Journal of Dairy Science, 86, 2462 (2003) 